\title{
Incidence of complications in dermatological surgery of melanoma and non-melanoma skin cancer in patients with multiple comorbidity and/or antiplatelet-anticoagulants. Five year experience in our Hospital
}

\author{
Incidencia de complicaciones en cirugía dermatológica de cáncer de piel melanoma y no \\ melanoma en pacientes con múltiple comorbilidad o antiagregantes-anticoagulantes. \\ Experiencia de nuestro hospital durante 5 años
}

Lilia Arguello-Guerra, Estefanía Vargas-Chandomid, Jose Manuel Díaz-González, Silvia Méndez-Flores, Ana Ruelas-Villavicencio and Judith Domínguez-Cherit*

Dermatology Department, Instituto Nacional de Ciencias Médicas y Nutrición Salvador Zubirán. Mexico City. Mexico

\begin{abstract}
Introduction: Surgery is performed more frequently now at days, due to the increasing incidence of melanoma and no-melanoma skin cancer. There are different opinions among dermatologic surgeons between to continue or discontinue antithrombotic therapy prior to the procedure, which increases the risk of thromboembolic events. Prophylaxis with oral antibiotics in the postsurgical period is controversial. Objective: To report the safety of surgery without suspending antithrombotic therapy and without oral antibiotic prophylaxis in dermatology surgery of patients with multiple comorbidities and polypharmacy. Method: We designed a retrospective study. We included a total of 655 patients; $96.6 \%$ had at least one comorbidity; $27.7 \%$ used aspirin and $4.3 \%$ some type of antithrombotic therapy. The most common type of skin tumor was basal cell carcinoma with $69.8 \%$. Results: The complication rate was $4.2 \%$; the most was wound dehiscence (1.1\%), followed by partial necrosis (0.9\%), infection (0.9\%), reaction to foreign body (0.6\%), complete necrosis $(0.3 \%)$, bleeding $(0.2 \%)$ and fistulae $(0.2 \%)$. Conclusions: Based on the literature and our experience, dermatologic surgery is safe without suspending antithrombotic therapy or antibiotic prophylaxis in patients with multiple comorbidity.
\end{abstract}

KEY WORDS: Dermatologic surgery. Skin cancer. Skin surgery complications. Antibiotic prophylaxis.

\section{Resumen}

Introducción: La cirugía es uno de los procedimientos que se realizan con mayor frecuencia en dermatología debido a la mayor incidencia de cáncer de piel melanoma y no melanoma. Se han encontrado distintas posturas entre los cirujanos dermatólogos sobre continuar o suspender antiagregantes y anticoagulantes antes del procedimiento, lo cual incrementa el riesgo de eventos tromboembólicos, además de la preferencia de utilizar profilaxis antibiótica de forma posquirúrgica por algunos dermatólogos. Objetivo: Reportar nuestra experiencia en cuanto a la seguridad de la cirugía dermatológica sin la suspensión de anticoagulantes/antiagregantes y sin profilaxis antibiótica en pacientes con múltiple comorbilidad y polifarmacia. Método: Se revisaron 655 pacientes. El 96.6\% tenían al menos otra enfermedad. El 27.7\% utilizaba ácido acetilsalicílico y el 4.3\% algún tipo de anticoagulante. El tipo de neoplasia más frecuente fue el carcinoma basocelular con 69.8\%. Resultados: La tasa total de complicaciones fue del 4.2\%. La complicación más frecuente fue la dehiscencia de la herida (1.1\%), seguida de

\author{
Correspondence: \\ *Judith Domínguez-Cherit \\ Vasco de Quiroga, 15 \\ Col. Sección XVI, Del. Tlalpan \\ C.P. 14080, Ciudad de México, México \\ E-mail: judom59@hotmail.com
}

Date of reception: 08-12-2016

Date of acceptance: 14-02-2018

DOI: 10.24875/CIRUE.M18000003
Cir Cir. 2018;86:15-23

Contents available at PubMed www.cirugiaycirujanos.com 
la necrosis parcial $(0.9 \%)$, la infección $(0.9 \%)$, la reacción a cuerpo extraño $(0.6 \%)$, la necrosis total $(0.3 \%)$, la hemorragia $(0.2 \%)$ y la fístula cutánea $(0.2 \%)$. Conclusiones: Basándonos en la literatura y nuestra experiencia, la cirugía dermatológica es segura sin suspender antitrombóticos ni indicar profilaxis antibiótica en pacientes con múltiple comorbilidad.

PALABRAS CLAVE: Cirugía dermatológica. Dermatología oncológica. Complicaciones posquirúrgicas. Profilaxis antibiótica.

\section{Introduction}

Surgery is one of the most commonly performed procedures in dermatology, due to the increased incidence of melanoma and non-melanoma skin cancer ${ }^{1,2}$. From superficial procedures, such as shaving, curettage and cryotherapy, to some of greater complexity, such as flaps and skin grafts are performed ${ }^{3}$.

Most dermatologic surgeons have different positions regarding antithrombotic medication discontinuation during dermatological surgery. Some choose to discontinue one week prior to the procedure, while others maintain perioperative antithrombotic medication ${ }^{4-7}$. The risk of discontinuation and its association with thrombotic events is higher than the benefit of stopping them ${ }^{6}$.

Overall, the most commonly reported complications of dermatological surgery include infection of the site of wound, loss of the graft or flap, hemorrhage and closure defects $^{8}$. The most common complication associated with the use of antithrombotic drugs is hemorrhage ${ }^{4-7}$.

Currently, the disproportionate use of antibiotics causes expenses to the health system, in addition to exposure to adverse effects and increased bacterial resistance ${ }^{9}$.

\section{Objective}

To report the safety of dermatological surgery without anticoagulants/antiaggregants discontinuation and without prophylactic use of antibiotics in patients with comorbidity and polypharmacy in our Institute.

\section{Outcomes}

- To demonstrate the overall low rate of complications, in comparison with previous similar studies.

- To demonstrate the low rate of infections without the use of prophylactic antibiotics.

- To demonstrate the low incidence rate of bleeding episodes without discontinuing antithrombotic treatments.

- To demonstrate the low rate of complications in flaps and grafts.
- To demonstrate the low rate of complications associated with smoking.

\section{Method}

\section{Study design}

- Retrospective study.

- Five years, from January 2011 to December 2015.

- One single center.

\section{Patients}

The inclusion criteria were:

- Patients diagnosed with melanoma and non-melanoma skin cancer who underwent any surgical procedure from January 1, 2011 to December 31, 2015.

- Only procedures performed by the dermatology department.

- Procedures carried out on an outpatient basis.

The exclusion criteria were:

- Patients with incomplete files.

- Patients without registration in the Institute.

- Patients without histological confirmation.

- Patients without postsurgical assessment.

- Procedures carried out by personnel from other specialties.

\section{Statistical analysis}

The procedures performed in our center were defined as clean surgery according to the Centers for Disease Control and Prevention (CDC) criteria ${ }^{10}$ :

- According to histology, the National Comprehensive Cancer Network (NCCN) guidelines for melanoma and non-melanoma skin cancer were considered for low, moderate and high risk ${ }^{11-13}$.

- By topography, it was classified as low and high risk according to the NCCN guidelines ${ }^{11-13}$.

- Neither the tumor size nor the surgical defect were considered.

- Antibiotic was not prophylactically used. 
- Included data were age, smoking, comorbidity, use of antithrombotic drugs, skin cancer type and location, and presence or absence of postsurgical complications.

In most patients, excision was performed with No. 15 scalpel blade with different types of closure:

- Direct closure.

- Advancement flap.

- Rotating flap.

- Transposition flap.

- Graft.

- Healing by secondary intention.

As for complications, they were defined as:

- Hemorrhage: presence of hematoma or persistence of bleeding within 24 hours after the procedure, requiring re-intervention to ligate a bleeding vessel or for hematoma drainage ${ }^{14}$.

- Infection: presence of purulent exudate, local temperature increase, perilesional erythema and progressive pain within the first 72 postoperative hours.

- Flap and graft necrosis: partial (necrosis up to $75 \%$ ) or total (necrosis greater than $75 \%$ ).

- Dehiscence: spontaneous opening of the wound with edges brought together with suture, without the presence of tissue necrosis.

- Erythema or foreign body reaction.

These events were documented in the medical record during the usual postsurgical assessment at 7-14 days (prior to removing the suture, during or after removal).

\section{Results}

Table 1 shows the baseline characteristics of our population. A total of 655 patients were assessed, out of whom $50.1 \%(n=328)$ were women and $49.9 \%$ $(n=327)$ were men; average age was 74 years. In the study population, $96.6 \%(n=633)$ was diagnosed with at least another disease, with a maximum of 12 and a mean of three; among these, the most common were systemic arterial hypertension $(48.1 \%, n=315)$, type 2 diabetes mellitus $(29.8 \%, n=195)$, dyslipidemia $(26.4 \%, n=173)$, solid organ and hematologic malignancy $(26.1 \% ; n=171)$, cardiovascular events $(18.9 \%$, $\mathrm{n}=124)$, immunosuppression induced by drugs or by human immunodeficiency virus infection (10.1\%, $\mathrm{n}=66)$, and solid organ transplantation $(7 \% ;=46)$. The presence of smoking at the time of surgery was documented in $12.8 \%(n=84)$ of patients.

The number of medications reported at the time of surgery ranged from 0 to 11 per patient (average of 3 )
Table 1. Population baseline characteristics

\begin{tabular}{lc}
\hline Characteristic & $\%(\mathbf{n})$ \\
\hline Total patients & $100(655)$ \\
Men & $49.9(327)$ \\
Women & $50.1(328)$ \\
Average age (range) & 74 years (20-101) \\
Healthy & $3.4(22)$ \\
& \\
Comorbidity & $96.6(633)$ \\
No comorbidity, average (range) & $3(0-12)$ \\
Type 2 diabetes mellitus & $29.8(195)$ \\
Systemic arterial hypertension (SAH) & $48.1(315)$ \\
Dyslipidemia (DLP) & $26.4(173)$ \\
Neoplasm & $26.1(171)$ \\
Cardiovascular & $18.9(124)$ \\
Inflammatory & $3.4(22)$ \\
Rheumatologic & $7(46)$ \\
Immunosuppression & $10.1(66)$ \\
Transplant & $7(46)$ \\
Smoking & $12.8(84)$ \\
\hline
\end{tabular}

Table 2. Description of total medications per patient. Antiaggregants and anticoagulants used during dermatologic surgery

\begin{tabular}{lc}
\hline Medications & $\%(\mathbf{n})$ \\
Average medications per patient & $3(0-11)$ \\
Antiaggregants & $28.1(184)$ \\
Acetylsalicylic acid & $27.2(177)$ \\
Clopidogrel & $1.2(8)$ \\
Anticoagulants & $4.3(28)$ \\
Acenocoumarin & $2.6(17)$ \\
Warfarin & $0.5(3)$ \\
Apixaban & $0.5(3)$ \\
Enoxaparin & $0.3(2)$ \\
Dabigatran & $0.3(2)$ \\
Rivaroxaban & $0.2(1)$ \\
\hline
\end{tabular}

(Table 2). The most frequent antiaggregant was acetylsalicylic acid (ASA) $(27.2 \%, n=177)$, followed by clopidogrel $(1.2 \%, n=8)$. Anticoagulants were reported in $4.3 \%(n=28)$ of patients, with acenocoumarin being the most common $(2.6 \% ; n=17)$.

The type of tumor that predominated was basal cell carcinoma of low $(24 \%, n=157)$ and high grade $(45.8 \%$, $\mathrm{n}=300$ ); the rest was distributed between squamous cell carcinoma (SCC) in situ (13.3\%, $n=87$ ), well-differentiated SCC $(9.3 \%, n=61)$, poorly differentiated SCC $(0.2 \%, n=1)$, melanoma in situ $(2.6 \% ; n=17)$, invasive melanoma $(3.4 \% ; n=22)$, porocarcinoma $(1.1 \% ; n=7)$, syringocystadenocarcinoma $(0.2 \% ; n=1)$, trichilemmal carcinoma $(0.2 \% ; n=1)$ and dermatofibrosarcoma protuberans $(0.2 \% ; n=1)$ (Table 3$)$. Similarly, by topography, localization in most patients was in high-risk areas $(56.5 \%)$ according to the NCCN classification. 

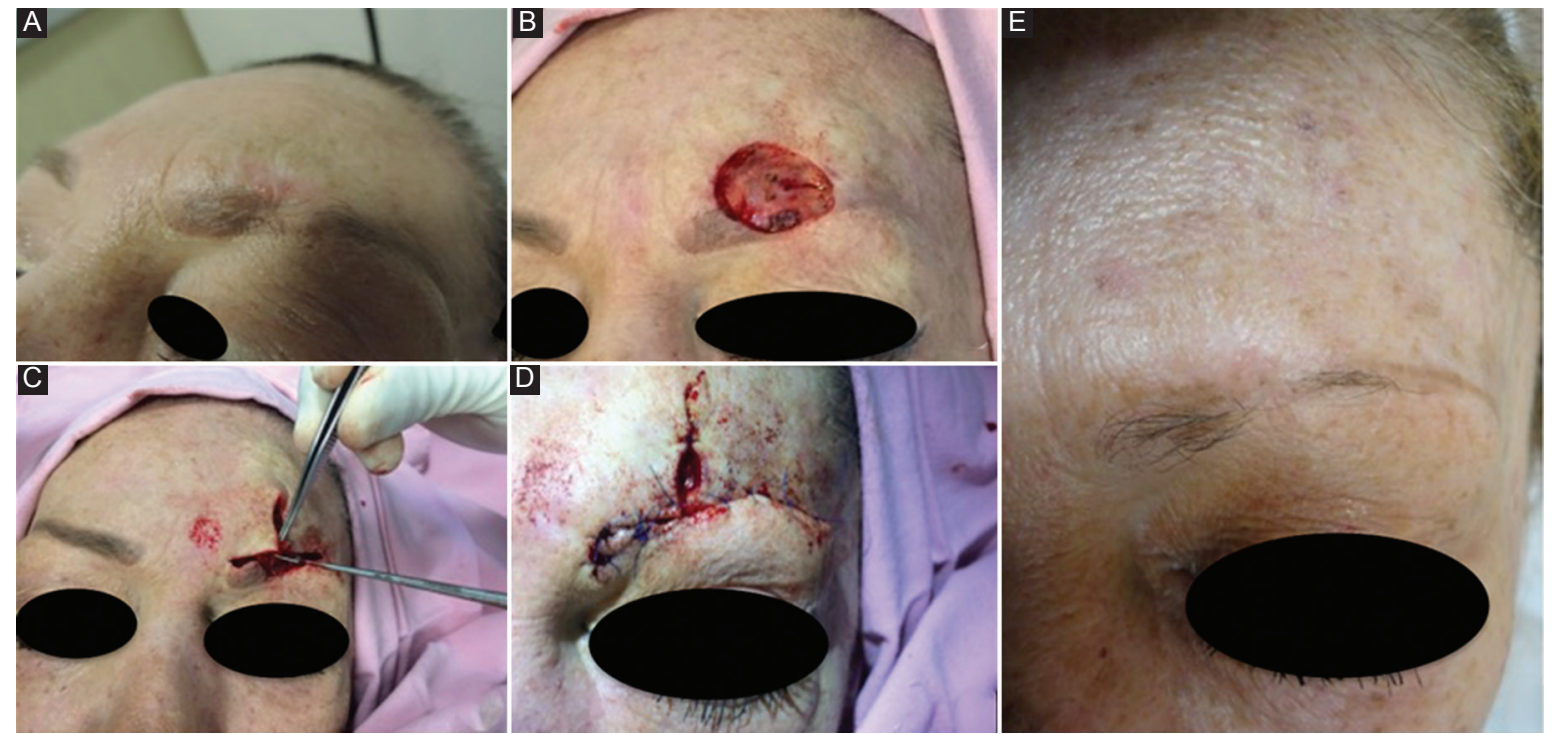

Figure 1. A: left supraciliar basal cell carcinoma. B: primary defect. C and D: "O-T" advancement flap. E: follow-up at 1 year.
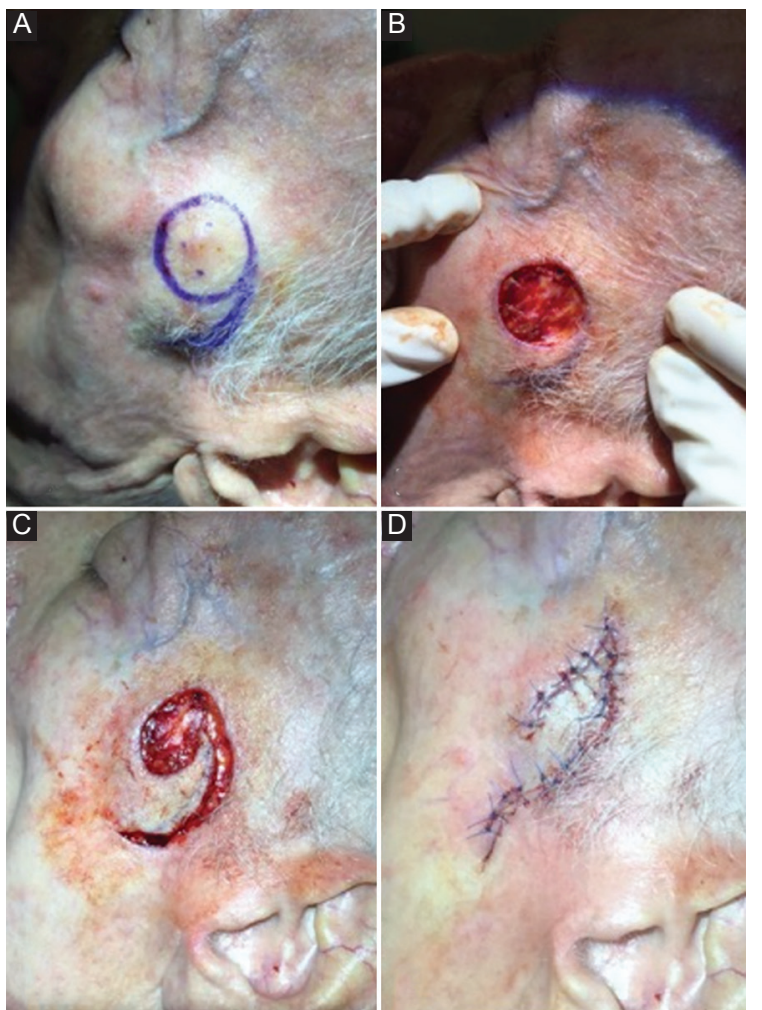

Figure 2. A: nodular basal cell carcinoma. B: primary defect. C: rotation flap. D: rotation flap closure.

In all 655 patients, excision was performed; in most of them $(99.1 \%)$, with a margin of at least $5 \mathrm{~mm}$; in the rest, widening of surgical margins was not completed because after postoperative assessment they did not attend a second surgical time. The types of closure that were most commonly used were direct closure $(82.9 \%, n=543)$, followed by different types of flaps, such as advancement flap (4.3\%, $\mathrm{n}=28)$ (Fig. 1),

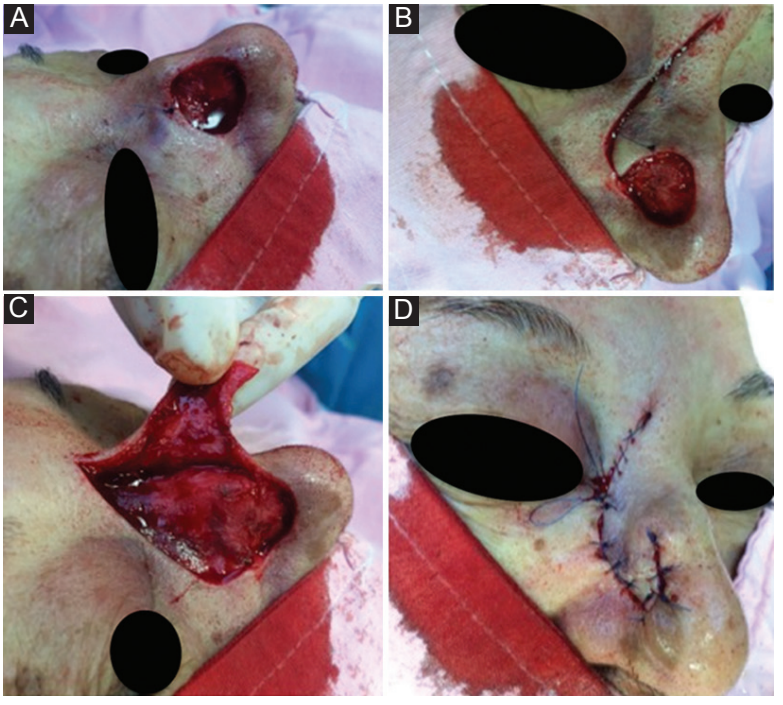

Figure 3. A: nodular basal cell carcinoma primary defect. B, C and D: rotation flap.

Table 3. Type of dry out tumors. Topography for low/high-risk.

\begin{tabular}{|c|c|}
\hline Type of tumors & $\%(n)$ \\
\hline Total tumors & $100(655)$ \\
\hline Low-risk BCC & $24(157)$ \\
\hline High-risk BCC & $45.8(300)$ \\
\hline SCC in situ & $13.3(87)$ \\
\hline Well-differentiated SCC & $9.3(61)$ \\
\hline Poorly differentiated SCC & $0.2(1)$ \\
\hline Melanoma in situ & $2.6(17)$ \\
\hline Invasive melanoma & $3.4(22)$ \\
\hline Porocarcinoma & $1.1(7)$ \\
\hline Syringocystadenocarcinoma & $0.2(1)$ \\
\hline Trichilemmal carcinoma & $0.2(1)$ \\
\hline Dermatofibrosarcoma protuberans & $0.2(1)$ \\
\hline Low-risk topography & $43.5(285)$ \\
\hline Hig-risk topography & $56.5(370)$ \\
\hline
\end{tabular}


Table 4. Type of surgical treatment, type of closure and type of complications

\begin{tabular}{lc}
\hline Surgical treatment & $\%(\mathbf{n})$ \\
\hline Excisional & $100(655)$ \\
With margin & $0.9(6)$ \\
Without margin & $99.1(649)$ \\
& \\
Type of closure & $82.9(543)$ \\
Direct & $4.3(28)$ \\
Advancement flap & $3.7(24)$ \\
Rotation flap & $1.7(11)$ \\
Transposition flap & $4.9(32)$ \\
Graft & $2.6(17)$ \\
Secondary intention & $4.2(27)$ \\
Complications & \\
Type of complication & \\
Hemorrhage & $0.2(1)$ \\
Partial necrosis & $0.9(6)$ \\
Total necrosis & $0.3(2)$ \\
Infection & $0.9(6)$ \\
Dehiscence & $1.1(7)$ \\
Foreign body reaction & $0.6(4)$ \\
Cutaneous fistula & $0.2(1)$ \\
\hline
\end{tabular}

rotation flap (3.7\%; $n=24)$ (Figs. 2 and 3 ) and transposition flap $(4.9 \%, n=11)$, graft $(4.9 \%, n=32)$ and healing by secondary intention $(2.6 \%, n=17)$. As regards complications, $4.2 \%$ was reported $(n=27)$ and in order of frequency, they were wound dehiscence $(1.1 \%, n=7)$, partial necrosis $(0.9 \%, n=6)$, infection $(0.9 \% ; n=6)$, foreign body reaction $(0.6 \% ; n=4)$, total necrosis $(0.3 \% ; n=2)$, hemorrhage $(0.2 \% ; n=1)$ and cutaneous fistula $(0.2 \% ; n=1)$ (Table 4).

Of the 27 patients in whom any complication was documented (Table 5), the only patient with a hemorrhage report was 72 years' old, it occurred on the nasal dorsum, he did not use antithrombotic drugs or tobacco, and only had one comorbidity. In six patients, partial necrosis was found, out of which three were recorded on the nasal dorsum (two with rotation flap and one with a graft), and only one of them with anticoagulant use; one was with direct closure on the scalp, another on the left leg and the other with a rotation flap on the left cheek. Of the two patients with total flap necrosis, one was documented on the nasal dorsum with use of ASA and the other on the left helix with graft. Regarding the site of infection, two were observed on the scalp, two on the arm and one on the mouth and genital area. Only one patient with arm surgery used ASA. Dehiscence occurred in seven patients, among which there were two in the trunk and one of each on the cheek, the leg, the ear, the temporal region and the chin. Of these, two patients (temporal area and ear) used ASA. Foreign body reaction was observed in two patients, one on the trunk and the other on the leg; the latter used ASA.

\section{Discussion}

The results of this review agree with those previously reported in similar studies ${ }^{15}$. Most procedures were performed by dermatologic surgeons and dermatology residents. Mohs micrographic surgery (MMS) was not performed. As part of our protocol, neither anticoagulants nor antiaggregants were discontinued in any procedure, according to the American Heart Association recommendations, and neither were systematic prophylactic antimicrobials indicated ${ }^{16}$.

Currently, the incidence of melanoma and non-melanoma skin cancer is increasing ${ }^{1,2}$. The older patients are, the more comorbidity they have, and thus they require the use of numerous medications, including those with antithrombotic and anticoagulant effects ${ }^{17,18}$.

The overall rate of recorded complications was similar to that of previous reports. The first study to compare MMS postoperative complications in patients using antithrombotic and non-steroidal anti-inflammatory drugs was that by Otley et al. ${ }^{19}$, including hemorrhage, dehiscence and flaps and grafts necrosis, with a rate of $4.58 \%$ being reported, similar to ours of $4.2 \%$

Infection is regarded as the presence of purulent exudate in addition to clinical data such as fever, erythema, edema, heat or induration present within the first 4-7 days after the surgical procedure ${ }^{10,20}$.

In our center, prophylactic antibiotics are not systematically used for this type of procedure, in accordance with the American Heart Association ${ }^{16}$ and American Academy of Orthopedic Surgeons guidelines, where procedures and anatomical and sites with high-risk for the development of infection are established.

CDCs consider dermatological surgery as a clean surgery, and calculate that, without the presence of inflammation and with a sterile technique, it has an infection risk lower than $5 \%{ }^{10}$. Comparing our infection rate of $0.9 \%$ with the figures reported in other studies (Table 6), we can observe that it does not differ from that observed with the use of antimicrobial prophylaxis, especially with the study by Maragh and Brown ${ }^{21}$, who analyzed 1115 tumors with MMS without the use of antimicrobial prophylaxis, with an infection rate of $0.7 \%$ being obtained.

The surgeries that require antimicrobial prophylaxis are those performed on mucous membranes and in sites with active infection at the time of the procedure. 
Cirugía y Cirujanos. 2018;86

Table 5. Postsurgical complications by topography, type of closure, smoking and antithrombotic use

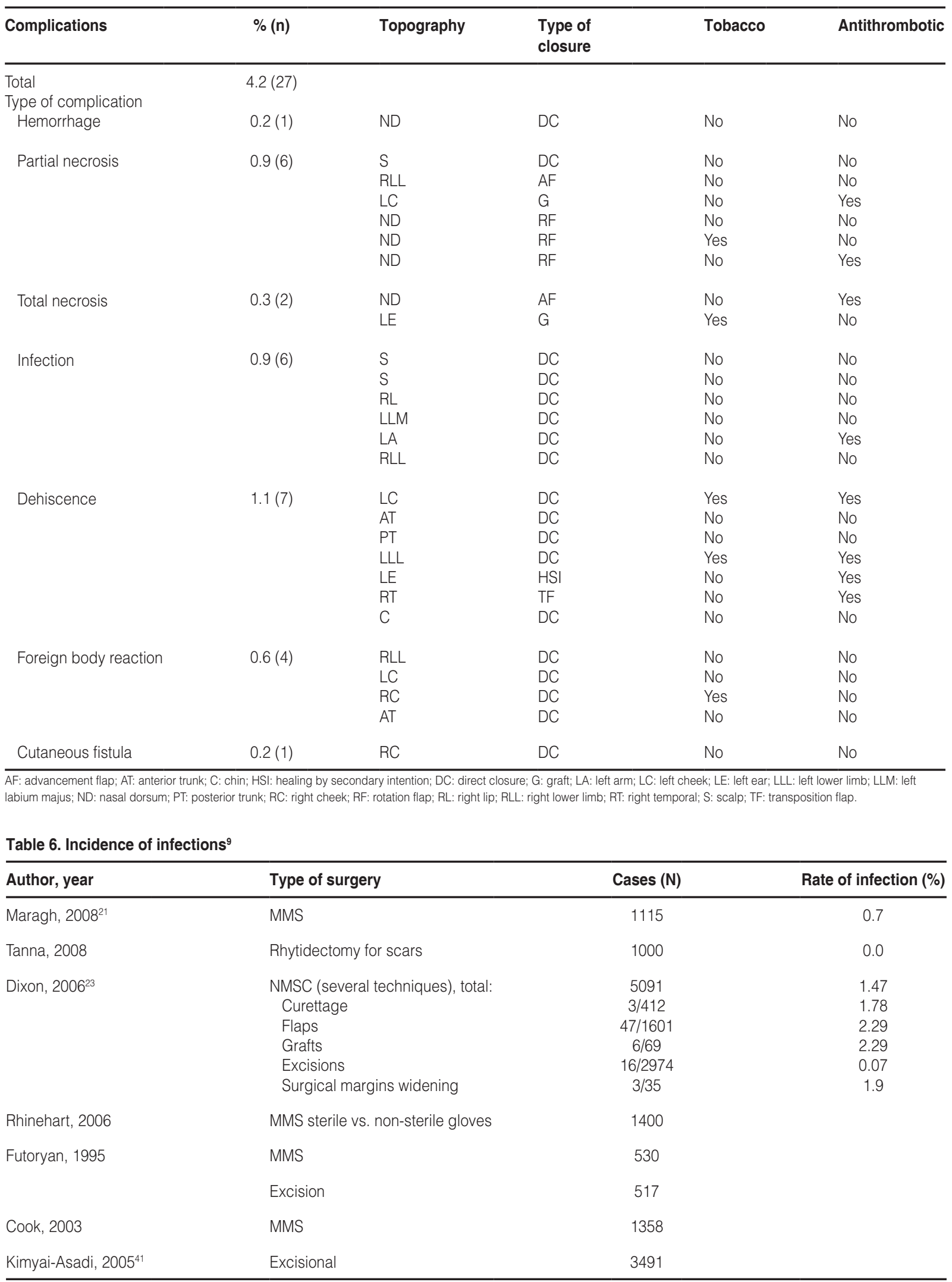

MMS: Mohs micrographic surgery; NMSC: non-melanoma skin cancer. 
By topography, the highest rate of complications has been reported on the lips, ears, inguinal region and in grafts and flaps in the nose, reaching up to $5 \% \%^{22,23}$.

In a more recent study with 69 patients, up to $17 \%$ of complications were reported to appear below the knee, highlighting that $8.9 \%$ of the totality were infected, while in the rest there was delayed healing, hypergranulation and poor healing ${ }^{24}$.

In our study, the patients who experienced infection were those who had scalp surgery (two patients), one in the mouth, one in the genital area and two in the arm.

Comorbidities that increase the risk of infection include pharmacological immunosuppression, diabetes and smoking; however, Dixon ${ }^{23}$ failed to demonstrate a significant difference between smokers and nonsmokers and their complications. Conversely, Wahie and Lawrence ${ }^{25}$ report that the rate of wound complications was significantly higher in smokers than in non-smokers: $63 \%$ vs. $12 \%$, respectively.

Most authors recommend personalizing the use of prophylaxis according to the procedure and topography, using a first-generation cephalosporin (prior to surgery). It should be noted that this is a recommendation based on procedures from other specialties ${ }^{9}$. Levender et al. ${ }^{26}$ retrospectively analyzed the use of topical antibiotics as prophylaxis in clean dermatological procedures performed by dermatologists and non-dermatologists, and observed that $6.0 \%$ and $3.5 \%$, respectively, use topical antimicrobial, with no difference in the outcome and therefore they propose to stop excessive use.

The results of our study support the recommendations not to use prophylactic antibiotic treatment preemptively, except in special cases, such as a history of cardiac and articular prostheses, and in surgery in sites with high risk of infection.

Surveys applied to doctors who perform skin surgery report that up to $50 \%$ always discontinue antithrombotic drugs prior to the procedure ${ }^{5,27}$. In our study, $28.1 \%$ of patients used antiaggregants and $4.3 \%$ some type of anticoagulation, which were continued during the procedure (Table 2). Only one patient with no history of antithrombotic therapy was reported to have experienced hemorrhage $(0.2 \%)$, which is a lower percentage than that referred in the study by Shimizu, et al. ${ }^{28}$, where only four patients $(0.53 \%)$ out of 760 experienced hemorrhage, which is a similar result to that of the study by Shipkov, et al. ${ }^{14}$, with only one patient with hemorrhage and anticoagulant use. Bordeaux, et al. ${ }^{29}$, in their study, reported $0.89 \%$ of hemorrhagic complications, most of them associated with the use of anticoagulants.
In our study, only nine of the 27 patients with complications used ASA, and one acenocoumarin. The complications that occurred include partial and total necrosis in three patients, infection in two patients, dehiscence in four patients and foreign body reaction in one.

Only few studies have been conducted in dermatological surgery comparing the use of this type of medications; however, in more complex surgeries, discontinuation is established in previous days. Some prospective studies have shown a low complication rate. For example, one of the first studies was the one by Bartlett, ${ }^{30}$ which compared 52 patients taking ASA with 119 patients without ASA, with $5.7 \%$ versus $7.5 \%$ of total complications, respectively, being obtained, and thus it is concluded that its use should not be discontinued for this type of procedures. In our study, the result was lower, since we only found $5 \%$ of complications in the total number of patients who used ASA (9 of 177).

As in previous studies, there was no increase observed in the risk of hemorrhage in patients with $\mathrm{ASA}^{18,28-34}$; conversely, thrombotic complications have been demonstrated when this type of medications are discontinued ${ }^{35,36}$.

We can claim that, at least in our study, hemorrhagic complications in patients with antiaggregants and anticoagulants are absent, which are the same findings reported by Alcalay ${ }^{37}$.

In our study, among $100 \%$ of smokers $(n=84)$, only $5.95 \%(n=5)$ had some type of complication: nose flap partial necrosis, ear flap total necrosis and two cases of dehiscence, one in the leg and another on the cheek, in addition to a foreign body reaction on the cheek that is attributed to the presence of suture.

In relation to tobacco, in flaps and grafts, it is important for the number of consumed packages per day (PPD) to be documented, since a dose-response relationship has been established between the number PPDs and the presence of necrosis. Goldminz and Bennett ${ }^{38}$ reviewed a series of 916 full-thickness skin grafts and grafts and found a significant dose-response relationship between the number of PPDs and the development of necrosis: smokers of one PPD had a two-fold higher risk of graft necrosis, whereas those with two PPD had a six-fold higher risk for developing necrosis in comparison with the population of nonsmokers, smokers of less than one PPD and former smokers $^{38}$. There is no consensus or guidelines that establish the time interval for tobacco cessation prior to surgery; most studies recommend from 1 day to 
4 weeks prior to surgery, resuming at between 5 days to up to 4 weeks postoperatively ${ }^{39}$. However, in those patients who were heavy smokers (more than one PPD), only $23 \%$ managed to completely discontinue its consumption for 4 weeks ${ }^{40}$; therefore, reducing the consumption to less than one PPD at least 1 week prior to surgery and 1 week afterwards is suggested $^{38}$.

Therefore, warning this type of patients about possible wound complications caused by smoking is recommended, and should be indicated to discontinue the use of tobacco at least 2 weeks prior and resume 1 week after surgery, during which nicotine replacement therapies can be used. In patients who are heavy smokers and who refuse to discontinue the habit, indicating a consumption lower than one PPD is recommended ${ }^{39}$.

Flaps and grafts partial necrosis occurred in $0.9 \%$ of these type of procedures (6/95), and total necrosis in $0.3 \%(n=2)$. The necrotic tissue was removed and the wound was left for healing by secondary intention. The anatomical sites were the scalp, lower limbs, cheek, nasal dorsum and ears. The rate of necrosis is lower when compared with other studies, such as the one by Bordeaux et al. ${ }^{29}$, with a $1.7 \%$ rate of partial necrosis (forehead, eyelid, nose and cheeks), without a relationship between site and necrosis being demonstrated, although partial necrosis of the graft in the nose and scalp did predominate.

As for dehiscence, we obtained a $1.1 \%$ rate $(n=7)$, with predominance in the face (nose and malar and temporal region), which is a slightly higher percentage than that reported in similar studies, with a rate of $0.73 \%{ }^{21}$ and with coinciding anatomical sites. Kimyai-Asadi et al. ${ }^{41}$ showed similar results to ours, although with MMS.

Standardized preoperative evaluation allows to beforehand evaluate he strategy to be followed for each patient ${ }^{42}$. Health status should be documented, and complications should be prevented according to comorbidities and medication intake, and postoperative risk should be assessed, as described by Otley ${ }^{43}$ in his proposal for preoperative assessment, which is similar to the procedure followed in our center.

\section{Limitations}

This was a retrospective, single-center study, and limited to 5 years, and therefore the population was only 655 patients. The number of cigarettes consumed at the time of surgery, tumor size or surgical defect were not documented.

\section{Conclusions}

Based on the literature and our experience, we conclude that dermatological surgery in patients with comorbidity and polypharmacy, including antiplatelet agents or anticoagulants, has the same complication rate, and discontinuation of any type of medication in outpatient procedures is therefore not recommended, because it surpasses the risk of a thrombotic event. Similarly, the low rate of infections without the use of prophylaxis was similar to the described reports and, therefore, systematic use of antibiotics is not recommended. Ambulatory dermatological surgery is safe in this type of patients without making modifications to established treatments.

\section{Ethical responsibilities}

Protection of people and animals. The authors declare that no experiments have been conducted on humans or animals for this research.

Confidentiality of data. The authors declare to have followed the protocols of their work center on the publication of patient data.

Right to privacy and informed consent. The authors have obtained informed consent from the patients and/or subjects referred to in the article. This document is in possession of the corresponding author.

\section{Funding}

No public or private funding was received.

\section{Conflict of interests}

There are no conflicts of interests involving any of the authors.

\section{References}

1. Universidad Nacional Autónoma de México. México: Boletín UNAMDGCS-362; c2016. (Actualizado el 26 de mayo de 2016; consultado el 11 de septiembre de 2016.) Disponible en: http://www.dgcs.unam.mx/ boletin/bdboletin/2016_362.html

2. American Cancer Society. Cancer Facts \& Figures 2016. Atlanta: American Cancer Society; 2016.

3. Roenigk RK. Dermatologists perform more skin surgery than any other specialist: implications for health care policy, graduate and continuing medical education. Dermatol Surg. 2008;34:293-300.

4. Alcalay J, Alkalay R. Controversies in perioperative management of blood thinnersin dermatologic surgery: continue or discontinue? Dermatol Surg. 2004;30:1091-4; discussion 1094.

5. Kovich O, Otley CC. Perioperative management of anticoagulants and platelet inhibitors for cutaneous surgery: a survey of current practices. Dermatol Surg. 2002;28:513-7.

6. Otley CC. Continuation of medically necessary aspirin and warfarin during cutaneous surgery. Mayo Clin Proc. 2003;78:1392-6. 
7. Callahan S, Goldsberry A, Kim H, Yoo S. The management of antithrombotic medication in skin surgery. Dermatol Surg. 2012;38:1417-26.

8. Council ML, Alam M, Gloster HM Jr, Bordeaux JS, Carroll BT Leitenberger JJ, et al. Identifying and defining complications of dermatologic surgery to betracked in the American College of Mohs Surgery (ACMS) Registry. J Am Acad Dermatol. 2016;74:739-45.

9. Shurman DL, Benedetto AV. Antimicrobials in dermatologic surgery: facts and controversies. Clin Dermatol. 2010;28:505-10.

10. Berríos-Torres SI. Evidence-based update to the U.S. Centers for Disease Control and Prevention and Healthcare Infection Control Practices Advisory Committee guideline for the prevention of surgical site infection: developmental process. Surg Infect (Larchmt). 2016;17:256-61.

11. Bichakjian CK, Olencki T, Aasi SZ, Alam M, Andersen JS, Berg D, et al. Basal cell skin cancer, version 1.2016, NCCN Clinical Practice Guidelines in Oncology. J Natl Compr Canc Netw. 2016;14:574-97.

12. Coit DG, Thompson JA, Algazi A, Andtbacka R, Bichakjian CK, Carson WE $3^{\text {rd }}$, et al. Melanoma, version 2.2016, NCCN Clinical Practice Guidelines in Oncology. J Natl Compr Canc Netw. 2016;14:450-73.

13. Bichakjian CK, Olencki T, Aasi SZ, Alam M, Andersen JS, Berg D, et al. Squamous Cell Skin Cancer, version 1.2016, NCCN Clinical Practice Guidelines in Oncology. J Natl Compr Canc Netw. 2016;14:574-97.

14. Shipkov H, Irthum $C$, Seguin $P$, Mojallal A, Braye F. Evaluation of the risk of post-operative bleeding complications in skin cancer surgery without interruption of anticoagulant/antithrombotic medication: a prospective cohort study. J Plast Surg Hand Surg. 2015;49:242-6.

15. Jarjis RD, Jørgensen L, Finnerup K, Birk-Sørensen L. Complications in skin grafts when continuing antithrombotic therapyprior to cutaneous surgery requiring skin grafting: a systematic review. J Plast Surg Hand Surg. 2015;49:129-34.

16. Wilson W, Taubert KA, Gewitz M, Lockhart PB, Baddour LM, Levison M, et al. Prevention of infective endocarditis: guidelines from the American Heart Association: a guideline from the American Heart Association Rheumatic Fever, Endocarditis and Kawasaki Disease Committee, Council on Cardiovascular Disease in the Young, and the Council on Clinical Cardiology, Council on Cardiovascular Surgery and Anesthesia, and the Quality of Care and Outcomes Research Interdisciplinary Working Group. J Am Dent Assoc. 2008;139(Suppl):3S-24S. Erratum in: J Am Dent Assoc. 2008;139:253.

17. Harrington RA, Becker RC, Ezekowitz M, Meade TW, O'Connor CM, Vorchheimer DA, et al. Antithrombotic therapy for coronary artery disease: the Seventh ACCP Conference on Antithrombotic and Thrombolytic Therapy. Chest. 2004;126(3 Suppl):513-48S.

18. Sabatine MS, Cannon CP, Gibson CM, López-Sendón JL, Montalescot G, Theroux P, et al. Addition of clopidogrel to aspirin and fibrinolytic therapy for myocardial infarction with ST-segment elevation. N Engl J Med. 2005;352:1179-89.

19. Otley CC, Fewkes JL, Frank W, Olbricht SM. Complications of cutaneous surgery in patients who are taking warfarin, aspirin, or nonsteroidal anti-inflammatory drugs. Arch Dermatol. 1996;132:161-6.

20. Messingham MJ, Arpey CJ. Update on the use of antibiotics in cutaneous surgery. Dermatol Surg. 2005;31:1068-78.

21. Maragh SL, Brown MD. Prospective evaluation of surgical site infection rate among patients with Mohs micrographic surgery without the use of prophylactic antibiotics. J Am Acad Dermatol. 2008;59:275-8.

22. Wright TI, Baddour LM, Berbari EF, Roenigk RK, Phillips PK, Jacobs MA, et al. Antibiotic prophylaxis in dermatologic surgery: advisory statement 2008. J Am Acad Dermatol. 2008;59:464-73.
23. Dixon AJ, Dixon MP, Dixon JB, Del Mar CB. Prospective study of skin surgery in smokers vs. nonsmokers. Br J Dermatol. 2009;160:365-7.

24. Honaker JS, Bordeaux JS, Tuttle MS. Retrospective review of risk factors predictive of complications in patients after below the knee mohs micrographic surgery. Dermatol Surg. 2016;42:568-70.

25. Wahie S, Lawrence CM. Wound complications following diagnostic skin biopsies in dermatology inpatients. Arch Dermatol. 2007;143:1267-71.

26. Levender MM, Davis SA, Kwatra SG, Williford PM, Feldman SR. Use of topical antibiotics as prophylaxis in clean dermatologic procedures. J Am Acad Dermatol. 2012;66:445-51.

27. Khadim MF, Bell PR, Rashid A, Lewis HG. A postal survey of UK practice on discontinuation of anticoagulant/antithrombotics therapy before minor cutaneous surgery of the head and neck. J Plast Reconstr Aesthet Surg. 2011;64:e213-5.

28. Shimizu I, Jellinek NJ, Dufresne RG, Li T, Devarajan K, Perlis C. Multiple antithrombotic agents increase the risk of postoperative hemorrhage in dermatologic surgery. J Am Acad Dermatol. 2008;58:810-6.

29. Bordeaux JS, Martires KJ, Goldberg D, Pattee SF, Fu P, Maloney ME. Prospective evaluation of dermatologic surgery complications including patients on multiple antiplatelet and anticoagulant medications. J Am Acad Dermatol. 2011;65:576-83.

30. Bartlett GR. Does aspirin affect the outcome of minor cutaneous surgery? Br J Plast Surg. 1999;52:214-6.

31. Kargi E, Babuccu O, Hosnuter M, Babuccu B, Altinyazar C. Complications of minor cutaneous surgery in patients under anticoagulant treatment. Aesthetic Plast Surg. 2002;26:483-5.

32. Syed S, Adams BB, Liao W, Pipitone M, Gloster H. A prospective assessment of bleeding and international normalized ratio in warfarin-anticoagulated patients having cutaneous surgery. J Am Acad Dermatol. 2004;51:955-7.

33. Shalom A, Wong L. Outcome of aspirin use during excision of cutaneous lesions. Ann Plast Surg. 2003;50:296-8.

34. Billingsley EM, Maloney ME. Intraoperative and postoperative bleeding problems in patients taking warfarin, aspirin, and nonsteroidal antiinflammatory agents. A prospective study. Dermatol Surg. 1997;23:381-3; discussion 384-5.

35. Schanbacher CF, Bennett RG. Postoperative stroke after stopping warfarin for cutaneous surgery. Dermatol Surg. 2000;26:785-9.

36. Kovich O, Otley CC. Thrombotic complications related to discontinuation of warfarin and aspirin therapy perioperatively for cutaneous operation. J Am Acad Dermatol. 2003;48:233-7.

37. Alcalay J. Cutaneous surgery in patients receiving warfarin therapy. Dermatol Surg. 2001;27:756-8.

38. Goldminz D, Bennett RG. Cigarette smoking and flap and full-thickness graft necrosis. Arch Dermatol. 1991;127:1012-5.

39. Gill JF, Yu SS, Neuhaus IM. Tobacco smoking and dermatologic surgery. J Am Acad Dermatol. 2013;68:167-72.

40. Chan LK, Withey S, Butler PE. Smoking and wound healing problems in reduction mammaplasty: is the introduction of urine nicotine testing justified? Ann Plast Surg. 2006;56:111-5.

41. Kimyai-Asadi A, Goldberg LH, Peterson SR, Silapint S, Jih MH. The incidence of major complications from Mohs micrographic surgery performed in office-based and hospitalbased settings. J Am Acad Dermatol. 2005;53:628-34.

42. Hansen TJ, Lolis M, Goldberg DJ, MacFarlane DF. Patient safety in dermatologic surgery: part I. Safety related to surgical procedures. J Am Acad Dermatol. 2015;73:1-12; quiz 13-4.

43. Otley CC. Perioperative evaluation and management in dermatologic surgery. J Am Acad Dermatol. 2006;54:119-27. 